Центр Российских Исследований RRC Working Paper Series

No. 30

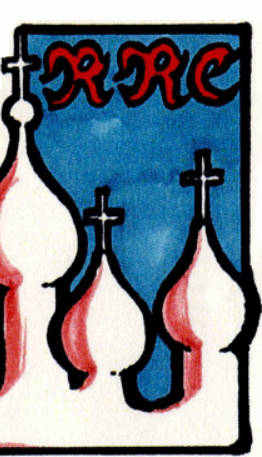

\title{
Russian Growth Path and TFP Changes in Light of the Estimation of Production Function using Quarterly Data
}

Masaaki Kuboniwa

January 2011

\section{RUSSIAN RESEARCH CENTER}

THE INSTITUTE OF ECONOMIC RESEARCH

HITOTSUBASHI UNIVERSITY

Kunitachi, Tokyo, JAPAN 


\author{
Russian Growth Path and TFP Changes \\ in Light of the Estimation of Production Function using Quarterly Data
}

\author{
Masaaki Kuboniwa \\ Institute of Economic Research \\ Hitotsubashi University
}

\begin{abstract}
We present estimations of a Cobb-Douglas production function with a steady change in TFP (total factor productivity) for the Russian economy, using quarterly data for the favorable period 1998Q3-2008Q2 and the period 1995Q1-2010Q2 as well. Compiling our baseline data on capital and labor adjusted for utilization, we explicitly present estimations of the coefficients (the capital distribution ratio and TFP) of production function, which show that TFP is the major growth source, followed by the capital contribution. We also show results of measurement of Russia's GDP gaps as the differences between potential and actual GDPs based on the production function and the Hodrick-Prescott filter.
\end{abstract}

JEL classification: E01, P24

Key words: Growth, TFP, Cobb-Douglas, Russia

\title{
1. Introduction
}

In this paper we characterize the Russian growth path for 1995Q1-2010Q2, estimating a Cobb-Douglas production function with the quarterly data. The literature concerning the Russian production function [de Broeck and Koen, 2000; Wilson and Purushothaman, 2003; Bessonov, 2004; Oomes and Dynnikova, 2006; Izyumov and Vahaly, 2008; Hanson, 2009] contributed to a better understanding of the Russian economic growth (contraction). However, all of them were not so satisfactory at the point that they employed annual data. Usually a production function is very sensitive to the data employed. Using annual data for a rather short period (10 years or so), we often face the situation that statistically (economically) meaningful results are not meaningful from the view point of economics (statistics). We show that the use of quarterly data 
relaxes this sensitivity problem.

Most of the literature also employed a conventional method of capital distribution ratio (capital share) of 30 percent or a rough estimate of the actual average capital share of 50 percent derived from the Russian national accounts. That is to say, they did not present any estimation of coefficients of the production function. These conventional assumptions should be tested by an explicit estimation of the Russian production function itself. An exception is found in Michaelides and Milos [2009]. Using quarterly data, they presented an estimation of a production function. However, as is shown in this paper, since their data with straightforward falls in the Russian capital and labor utilized are questionable, their estimation of the markedly high TFP contribution to the Russian growth for 1994-2006 cannot be acceptable.

In addition, most of the literature did not clearly show the compilation processes and sources of the data on capital stock. The lack of appropriate data including capital stock has stood in the way of further progress of the research on the Russian economy, based on a production function. Our attempts cannot be free from this constraint. Nevertheless, here we would like to present results of the estimation of a production function, which are at least meaningful from the view points of both statistics and economics, to constitute a step toward further investigation. We also provide a clear exposition of estimations of the Russian capital stock.

Some of the preceding papers, including Oomes and Dynnikova [2006], suggested the importance of utilization rates of primary factor inputs. We also present estimations of a production function using data on capital and labor adjusted for utilization in REB (Russian Economic Barometer) [2010, Vol. 2, p.49]. We rely upon the REB utilization rate of capital in the following, whereas our baseline estimate of labor adjusted is not based, on the REB utilization rate of labor, but on the official employment rate which is defined as the share of the actual employment in the official 'economically active population (labor force).'

The measurement of GDP gaps is important to understand the actual and potential properties of the Russian growth path. In the literature several methods to measure GDP gaps are well known. Here we employ two methods based on the production function estimated and the so called Hodrick-Prescott filter.

What we present in the following is only a report on simple exercises of OLS regressions for the Russian economy. However, as is suggested in the preceding studies, this report provides essential and useful information in considering present and future business climate of the Russian economy which is one of the world largest emerging markets. 


\section{A Cobb-Douglas Production Function and Data for its Estimation}

We employ a Cobb-Douglas production function with a steady exogenous technical progress as follows:

$$
Y=A \exp (\lambda t) K^{\alpha} L^{(1-\alpha)}
$$

where $Y=$ the real GDP , $K$ and $L=$ the real capital stock and labor respectively, $\alpha=$ the GDP elasticity with respect to capital (the capital distribution ratio; $1>\alpha>0$ ), $\lambda=$ the positive constant technical progress rate or the total factor productivity (TFP); $A=\mathrm{a}$ positive constant.

Since this function is homogeneous of degree 1 with respect to $K$ and $L$, we can write it as follows:

$$
y=A \exp (\lambda t) k^{\alpha},
$$

where $y=Y / L$ and $k=K / L$. It follows from this that

$$
\log y=\alpha \log k+\lambda t+\log A .
$$

We estimate coefficients $\alpha, \lambda$ and a constant $\log A$ by using OLS based on the Russian quarterly data.

When we denote the growth rate of a variable $X$ as $\mathrm{g}(X)=d X / X$, from the production function we have the following well known growth accounting equation:

$$
\mathrm{g}(Y)=\alpha \mathrm{g}(K)+(1-\alpha) \mathrm{g}(L)+\lambda,
$$

where $\mathrm{g}(Y), \mathrm{g}(K)$ and $\mathrm{g}(L)$ denote the growth rate of real GDP, the increment rates of capital and labor respectively. The first and second terms of the right-hand side of this equation show the capital and labor contributions to GDP growth respectively. The last term presents the TFP contribution to GDP growth which measures the effects of resource reallocations, modernization, technical progress, and catch-up efforts in the Russian economy.

We are now in a position to compile the data on GDP, capital and labor in a well defined manner. Real quarterly GDP data at 2003 prices can be estimated, based on the official non-seasonally-adjusted (nsa) values for 2003Q1-2010Q2 at the reference year 
2003 (the Rosstat website, www.gks.ru, as of October 1, 2010) and the official growth rates (nsa) for 1996Q1-2003Q4 (Archives of the Rosstat website as of December 31, 2009). ${ }^{1}$ We convert these estimated data into the seasonally adjusted (sa) data through the so called census $\mathrm{X}-12$ as is shown as the real GDP $(Y)$ in Figure 1.

[Figure 1 here]

One of the most difficult tasks for the estimation of a production function may be to compile the data on capital stock. We estimate the capital stock time series at 2003 prices by using the following equation.

$$
K_{1, t}=K_{1, t-1}(1-\delta)+I_{t}
$$

where $K_{1, t}$ is real fixed capital stock measured in 2003 constant prices at the end of the period $t, I_{t}$ is the real investment (fixed capital formation) measured in 2003 prices at the period $t$, and $\delta$ is a constant depreciation rate. $K_{1, t}$ can be regarded as the capital non-adjusted for utilization, that is to say, capital with the full utilization rate.

In the estimation of capital stock, the official SNA investment data were seasonally adjusted as in the case of GDP. Figure 1 also shows data (nsa and sa) on investment at 2003 prices.

We regard the initial value of the fixed capital stock at the end of 2002Q4 (that is to say, at the beginning of the year 2003) as 52,904 billion rubles at current prices which may be 1.7 times higher than the official value of overall capital stock of 30,329 billion rubles at book prices. Our initial value is based on the data that Rosstat preliminarily compiled in accordance with 2003 input-output tables. The data employed is preliminary, while we think that it reflects the current values for the reproduction of corresponding capital stocks better than the official value at mixed book prices.

Our baseline assumption of the depreciation rate per annum is 1.8 percent (the quarterly rate of 0.45 percent), which corresponds to the ratio of the capital depreciation (consumption of capital stock) to the capital stock for 2003. The value of capital depreciation in 2003, which is derived from the official integrated SNA table, amounts to 959 billion rubles at current prices (the Rosstat website). Hence we have the annual depreciation rate of 1.8 percent $(959 / 52,904=0.018)$. Thus we have our time series (levels) of the Russian capital stock non-adjusted.

A monotonically increasing trend of capital non-adjusted irrespective of

\footnotetext{
${ }^{1}$ The official quarterly GDP data for Russia are available only from 1995 onwards.
} 
fluctuations of investment is due to the fact that the capital $K_{1, t}$ increases if the investment $I_{t}$ is greater than the capital replacement $\delta K_{1, t-1}$. This is true even in the case of decreasing investment. Our annualized growth rates of the Russian capital stock non-adjusted are much higher than the official growth rates at 2000 constant prices (the Rosstat website). We can suggest several factors for this difference. In estimating the official real growth rates of fixed capital Rosstat may employ the value of capital stock at the base year 2000 which is much higher than its value we assume. In the official estimation Rosstat may employ data on "fixed capital put into operation" as $\left\{I_{t}\right\}$ which are much less than those on fixed capital formation in the national accounts. These suggestions depend on further investigation.

We estimate quarterly data of labor in the unit of persons for 1995Q1-2010Q2, using the official monthly reports named Russian Social and Economic Position (SEP) which have been based on Labor Survey (LS). We estimate labor non-adjusted $\left(L_{1}\right)$ or with full employment from the 'economically active population' which includes both employed and unemployed persons of 15 to 72 years old in SEP. The aggregated quarterly data (nsa) in SEP are seasonally adjusted through X-12.

Utilization rates of capital and labor are rather important in the estimation of the production function. Figure 2 shows the seasonally adjusted utilization rates of capital and labor of the whole industry $\left(U_{K, R E B}\right.$ and $\left.U_{L, R E B}\right)$ given by REB. Figure 2 also displays seasonally adjusted data based on the official employment rates (utilization rate of labor; $\left.U_{L, 2}\right)$ which are calculated as the shares of actually employed persons $\left(L_{2}\right)$ given by SEP in the labor force $L_{1} ; U_{L, 2}=L_{2} / L_{1}$. In addition to seasonal adjustments we adjust the actual quarterly employment by using the 'annual average employment' (Rosstat website) as the control totals to exclude persons for maternity leave and child-care from employment.

[Figure 2 here]

Due to the lack of appropriate data we use the REB industrial utilization rate of capital as a proxy of the overall utilization rate of capital. The value of correlation coefficient between the annual industrial utilization rates in REB and Rosstat (website) is very high $(0.985)$ for 1995-2009. Figure 3 shows data on capital non-adjusted $\left(K_{1}\right)$ and adjusted for utilization $\left(K_{2}=U_{K, R E B} K_{1}\right)$. The value of correlation coefficient between the quarterly utilization rates of capital and labor in REB is also very high (0.957), while this parallel movement is not necessarily appropriate in estimating the production function where the major independent variable is the capital-labor ratio. 
As for labor we use the REB utilization rate $U_{L, R E B}$ as well as $U_{L, 2}$. Figure 4 shows labor non-adjusted $\left(L_{1}\right)$, labor adjusted for actual employment $\left(L_{2}=U_{L, 2} L_{1}\right)$ and labor adjusted for the REB industrial utilization $\left(L_{3}=U_{L, R E B} L_{1}\right)$.

[Figure 3 here]

[Figure 4 here]

\section{Estimations of the Production Function}

First, let us estimate the production function by using the actual GDP and the non-adjusted capital and labor $\left(Y, K_{1}, L_{1} ; y_{1}=Y / L_{1}\right.$, and $\left.k_{1}=K_{1} / L_{1}\right)$ for 1998Q3 (bottom) - 2008Q2 (peak). Then we have the following result with coefficients at the 1 percent significance level (details of the regressions in this paper are given in the Appendix):

$$
\begin{aligned}
& \log y_{1}=\alpha \log k_{1}+\lambda t+\log A ; \\
& \mathrm{g}(Y)=0.75 * \mathrm{~g}\left(K_{1}\right)+0.25^{*} \mathrm{~g}\left(L_{1}\right)+0.011 \text { (annualized TFP of } 4.6 \text { percent). }
\end{aligned}
$$

These variables are not spuriously related but cointegrated (all results of unit root tests for the variables and regressions in this paper are also shown in the Appendix).

In the case of non-adjusted capital and labor we have a high value of capital distribution ratio of 75 percent which is slightly higher than that of the actual average capital distribution ratio before deduction of 'hidden' labor income (67 percent) for 1999-2008, based on annual reports of National Accounts of Russia (NAR).

The average annual growth rates of the Russian GDP $(Y)$, capital stock $\left(K_{1}\right)$ and labor force $\left(L_{1}\right)$ for 1998Q3-2008Q2 were 7.6 percent, 3.1 percent and 0.5 percent, respectively. The capital contribution to the growth $(0.75 * 3.1=2.3$ percentage points $)$ explains 30 percent of the overall growth rate, while the labor contribution to the growth $(0.25 * 0.5=0.1$ percentage point $)$ explains only 2 percent of the overall growth rate. The residual of 68 percent consists of the TFP (61 percent) and statistical error ( 7 percent). ${ }^{2}$ More than two-third of the growth can be explained by the TFP impact, whereas the remaining one-third of the growth can be explained by the capital contribution.

Next, let us estimate the production function by using the actual GDP and the

\footnotetext{
${ }^{2}$ In this paper we distinguish TFP (estimated $\lambda$ ) from statistical error in the total residual. This may be different from the usual convention where the total residual is regarded as TFP.
} 
capital adjusted for utilization (REB) and labor (actual employment) ( $Y, K_{2}, L_{2} ; y_{2}=Y$ / $L_{2}$, and $k_{2}=K_{2} / L_{2}$ ) for 1998Q3 (bottom)-2008Q2 (peak). Then we have the following result with coefficients at the 1 percent significance level:

$$
\begin{aligned}
& \log y_{2}=\alpha \log k_{2}+\lambda t+\log A ; \\
& \mathrm{g}(Y)=0.39 * \mathrm{~g}\left(K_{2}\right)+0.61 * \mathrm{~g}\left(L_{2}\right)+0.010 \text { (annualized TFP of } 4 \text { percent). }
\end{aligned}
$$

The capital distribution ratio is about 40 percent which is much less than the actual average capital distribution ratio after deduction of 'hidden' labor income ( 55 percent) for 1999-2008 based on NAR, while this capital distribution ratio may be plausible for a developing economy.

The average annual growth rates of the Russian GDP $(Y)$, capital stock $\left(K_{2}\right)$ and labor force $\left(L_{2}\right)$ for 1998Q3-2008Q2 were 7.6 percent, 7.6 percent and 0.8 percent, respectively. The capital contribution to the growth $(0.39 * 7.6=3.0$ percentage points $)$ explains 39 percent of the overall growth rate, while the labor contribution to the growth $(0.61 * 0.8=0.5$ percentage point $)$ explains 7 percent of the overall growth rate. The residuals of 54 percent consist of the TFP (53 percent) and statistical error (1.5 percent). Still more than one half of the growth can be explained by the TFP impact, whereas two-fifth of the growth can be explained by the capital contribution. In use of the REB adjusted capital the increment rate of capital becomes much greater than in use of the non-adjusted capital, which results in a lower capital distribution ratio. The TFP impact in this case becomes weaker in comparison with the case of non-adjusted capital and labor, while the role of the capital contribution becomes greater.

When we use non-adjusted capital $\left(K_{1}\right)$ and $k_{2 \mathrm{a}}=K_{1} / L_{2}$ in Equation (2) in place of adjusted capital $\left(K_{2}\right)$ and $k_{2}$, we have the following coefficients at the 1 percent significance level for 1998Q3-2008Q2:

$$
\begin{aligned}
& \log y_{2}=\alpha \log k_{2 \mathrm{a}}+\lambda t+\log A ; \\
& \mathrm{g}(Y)=0.64 * \mathrm{~g}\left(K_{1}\right)+0.36 * \mathrm{~g}\left(L_{2}\right)+0.011 \text { (annualized TFP of } 4.6 \text { percent). }
\end{aligned}
$$

This capital distribution ratio of 64 percent is close to the official average ratio of 67 percent before the deduction of 'hidden' labor income for 1999-2008 based on NAR. The TFP contribution of 4.6 percent equals that in the case of non-adjusted capital and labor in Equation (1).

For the favorable period 1998Q3-2008Q2, we also estimate the production function using the labor adjusted for the REB utilization $\left(L_{3}=U_{L, R E B} L_{1}\right)$ in addition to $Y$ 
and $K_{2}\left(y_{3}=Y / L_{3}, k_{3}=U_{K}\right.$ REB $\left.K_{1} / L_{3}\right)$. Then we have the following result with coefficients at the 1 percent significance level:

$\log y_{3}=\alpha \log k_{3}+\lambda t+\log A$

$\mathrm{g}(Y)=0.34 * \mathrm{~g}\left(K_{2}\right)+0.66 * \mathrm{~g}\left(L_{3}\right)+0.008$ (annualized TFP of 3.4 percent).

The capital distribution ratio of 34 percent is just close to a conventional ratio (33 percent).

When we adjust the official labor force by using the REB labor utilization rate, the average annual growth rate of the labor adjusted accounts for a rather high value of 3.1 percent for 1998Q3-2008Q2. Thus the labor contribution to the growth also shows a high value of 2.1 percentage points $(0.66 * 3.1=2.1)$ although it is still smaller than the TFP contribution of 3.4 percentage points and the capital contribution of 2.6 percentage points $(0.34 * 7.6=2.6)$ as well. This situation is due to a low value of the REB labor utilization rate of 72.7 percent in 1998Q3 which might need further investigation.

Here let us estimate the production function for the period 1995Q1-2010Q2 including the 1998 financial crisis and the 2008-2009 Lehman shock coupled with the adverse oil shock. We cannot obtain any meaningful result for Equation (3) with $\left\{y_{3}\right.$, $\left.k_{3}\right\}$. For Equation (2) with $\left\{y_{2}, k_{2}\right\}$ we have the satisfactory result with coefficients at the 1 percent significance level as follows:

$$
\mathrm{g}(Y)=0.44 * \mathrm{~g}\left(K_{2}\right)+0.56 * \mathrm{~g}\left(L_{2}\right)+0.006 \text { (annualized TFP of } 2.5 \text { percent). }
$$

The capital distribution ratio through the Russian business cycles for 1995Q1-2010Q2 accounts for 44 percent which is rather close to that for the favorable period 1998Q3-2008Q2. The TFP contribution of 2.5 percentage points through all business cycles is much less than that of 4 percentage points for the favorable period.

The average annual growth rates of the Russian GDP $(Y)$, capital stock $\left(K_{2}\right)$ and labor employment $\left(L_{2}\right)$ for 1995Q1-2010Q2 were 3.6 percent, 4.0 percent and 0.2 percent, respectively. The capital contribution to the growth $(0.44 * 4.0=1.8$ percentage points) explains 48.5 percent of the overall growth rate, while the labor contribution to the growth $(0.56 * 0.2=0.1$ percentage point $)$ explains only 3.5 percent of the overall growth rate. The residuals of 1.8 percentage points (share 48 percent) consist of the TFP contribution of 2.5 percentage points (share 68 percent) and statistical error of -0.7 percentage point (share -20 percent). Two-third of the growth can be explained by the TFP impact, while one half can be explained by all residuals. 
Another half of the growth can be explained by the capital contribution. As is stated, in use of the REB adjusted capital the increment rate of capital becomes much greater than in use of the non-adjusted capital. The TFP impact in this case is still very strong although the statistical error of residuals is rather large.

Why do the data $\left\{y_{2}, k_{2}\right\}$ yield an estimation of the production function for 1995Q1-2010Q2 much better than $\left\{y_{3}, k_{3}\right\}$ ? Figures 5 shows movements of labor productivity and capital-labor ratio based on $\left\{y_{2}, k_{2}\right\}$, whereas Figure 6 shows those based on $\left\{y_{3}, k_{3}\right\}$. As is shown, for $\left\{y_{2}, k_{2}\right\}$ labor productivity and capital-labor ratio are well correlated. However, for $\left\{y_{3}, k_{3}\right\}$ they are not well correlated from 2008Q4 onwards. This might suggest that the REB labor utilization rate for industry is not a good proxy of the overall utilization rate. As, unlike capital utilization rate, labor employment rate cannot be so flexible in general, the use of actual overall employment rate may be better than that of the REB industrial labor utilization rate in estimating the production function based on the actual GDP. Needless to say, the compilation and selection of data $\{y, k\}$ needs further consideration.

[Figure 5 here]

[Figure 6 here]

Table 1 summarizes our exercises of the Russian growth accounting. Figures 7 and 8 display actual and fitted GDPs based on Equation (2) for 1998Q3-2008Q2 and 1995Q1-2010Q2 respectively. The actual GDP is just close to the fitted GDP for the favorable period 1998Q3-2008Q2. Similar results can be seen for Equations (1) and (3) as are shown by high values of adjusted $R^{2}$ (see Table A1 in the Appendix). The deviation of actual GDP from fitted GDP is slight but visible for 1995Q1-2010Q2. In particular, for the final stage of the favorable period the actual GDP is larger than the fitted GDP. In contrast for the recent recovery period 2009Q4-2010Q2 the actual GDP is smaller than the fitted GDP.

[Table 1 here]

[Figure 7 here]

[Figure 8 here]

\section{Measurements of GDP Gaps}

A maximal potential GDP series $\left\{Y^{*}\right\}$ using the estimates of the production 
function based on Equation (2) for 1995Q1-2010Q2 can be computed as follows:

$$
Y^{*}=A \exp (\lambda t)\left(\max \left\{U_{K, R E B}\right\} K_{l}\right)^{\alpha}\left(\max \left\{U_{L, 2}\right\} L_{1}\right)^{1-\alpha},
$$

where $\alpha=0.394, \lambda=0.010, A=0.053, \max \left\{U_{K, R E B}\right\}=81.5$ percent for 2008Q1 and $\max \left\{U_{L, 2}\right\}=92.3$ percent for 2010Q2.

We also would like to present another potential GDP series $\left\{Y^{* * *}\right\}$ using the so called Hodrick-Prescott filter. The conceptual framework presented by Hodrick and Prescott [1997] can be summarized as follows.

The actual GDP series $\{Y(t)\}$ is the sum of growth component $Y^{* *}(t)$ and cyclical component $C(t)$.

$$
Y(t)=Y^{* *}(t)+C(t)
$$

The growth component $Y^{* * *}(t)$ is derived from solving the optimization problem:

$$
\min \left\{\Sigma_{t} C(t)^{2}+\mu \Sigma_{t}\left[d Y^{* *}(t)-d Y^{* *}(t-1)\right]^{2}\right\}
$$

where $d Y^{* *}(t)=Y^{* *}(t)-Y^{* *}(t-1)$ and $\mu$ is a positive number penalizing the variability of the growth component series. We employ a conventional value of $\mu$ of 1600 for quarterly data. Thus our potential growth path $\left\{Y^{* * *}\right\}$ is given by the solution of this problem.

Figure 9 shows actual and potential GDP series $\left\{Y, Y^{*}, Y^{* *}\right\}$. From this Figure we can state as follows:

First, we find the fact that the potential GDP $Y^{*}$ based on Equation (4) is always greater than another potential GDP series $\left\{Y^{* *}\right\}$ using the Hodrick and Prescott filter for 1995Q1-2010Q1 although the difference between two potential GDP series is rather small for 2005Q1-2008Q2.

Second, the potential GDP series $\left\{Y^{* *}\right\}$ is very close to the actual GDP series $\{Y\}$ except for the periods of the 1998 crisis and 2008-2009 shocks. In other words the potential GDP series $\left\{Y^{* *}\right\}$ based on the Hodrick and Prescott filter reflects the Russian growth trends in a well defined manner. In 2010 the actual GDP has been getting close to the growth trend based on the Hodrick and Prescott filter. Using the preliminary data on the Rosstat website as of February 1, 2011 the actual GDP has already caught the potential GDP based on the Hodrick and Prescott filter at the end of 2010.

Third, for 2006Q4-2008Q3 both potential series $\left\{Y^{*}, Y^{* *}\right\}$ exceed the actual series 
$\{Y\}$. This suggests that during the period for 2006Q4-2008Q3 the Russian economy met an overheated cycle. This overheat is considered to be compensated for by the recession from 2008Q4 onwards.

Fourth, the annual average growth rates of $\left\{Y^{*}\right\}$ and $\left\{Y^{* *}\right\}$ for 1995Q1-2010Q2 are 3.9 percent and 4.0 percent respectively both of which are slightly higher than the actual rate of 3.6 percent. The potential growth rate of the Russian economy in the long run is about 4 percent. The fact that the potential GDP level based on the production function at the initial period is much higher than its actual level results in its slow growth.

[Figure 9 here]

\section{Concluding Remarks}

In the Soviet era, noted estimations of production functions appeared as is shown in Weitzman [1970]. Former Soviet republics including Russia met a great contraction of GDP after the collapse of the USSR. An analysis of an economy without any GDP growth cannot be meaningful through neoclassical growth models which assume the steady growth of an economy in the long run. From 1999 to 2008 Russia experienced the favorable growth period, which gives us an opportunity to study its growth through a production function. In addition, now quarterly data on GDP, investment and labor for Russia are available.

We explicitly presented estimations of a Cobb-Douglas production function with a steady technical progress using the Russian quarterly data. Surprisingly, in the literature any satisfactory estimation of a production function for the Russian economy has not yet appeared within our knowledge. Our attempt suggests that we had better employ quarterly data in estimating the Russian production function.

Estimating parameters of the production function based on inputs without adjusting for utilization, we showed that for the favorable period 1999-2008 the key growth drive from the supply-side appeared to be the TFP, followed by the capital contribution. Without adjusting for utilization the favorable growth rate of 7.6 percent was induced by the TFP growth rate of 4.6 percent. A large TFP level implies Russia's strong efforts for modernization and catch-up in the process of economic growth. Our result might well be in accordance with Wilson and Purushothaman [2003]'s pioneering work on BRICs.

We also showed that based on inputs with adjusting for utilization we reach 
another understanding of the Russian growth path. For both the favorable period 1999-2008 and for the whole period 1995-2010 the major growth source remained to be the TFP contribution, followed by the capital contribution. With adjusting for utilization the favorable growth rate of 7.6 percent was induced by the TFP growth rate of 4 percent and the capital contribution of 3 percent. The average growth rate of 3.6 percent for 1995-2010 was also brought about by the TFP contribution of 2.5 percent and the capital contribution of 1.8 percent. The difference between the TFP and capital contributions with adjusted capital becomes smaller in comparison with non-adjusted capital. This is due to the increment of adjusted capital much greater than that of non-adjusted capital. Given the GDP growth rate, higher contributions of capital and labor lead to a lower TFP contribution, while TFP remains to be important as the major source for the Russian growth. We should pay attention to both of capital and TFP contributions to the Russian growth.

In the long run the Russian TFP change is around 2.5 percent, and the capital distribution ratio, or the GDP elasticity with respect to capital changes, is about 40 percent. In the favorable period the TFP change can be raised up to about 5 percent.

Our assumption on the utilization rates for industry as proxies for the overall economy should be relaxed because the key sectors for the Russian growth are not only industry but also services including the trade sector. In particular the REB utilization rate for labor does not provide any good data in estimating our production function. As another proxy for the capital utilization of the entire economy we can consider an index reflecting the terms-of-trade effects. As is shown by Kuboniwa [2010], the Russian economic growth of the manufacturing and trade sectors heavily depends on changes in oil prices. The terms-of-trade or the trading gains can be alternative proxies because we can assume that all Russian managers of enterprises and factories and most of foreign investors would make decisions of their capital utilization rates or investment in response to changes in oil prices or terms-of-trade effects. In fact, the movement of the REB utilization rate of capital is well explained by changes (USD / bbl) in oil prices for 1995Q1-2009Q4 (data of Urals oil prices from Bloomberg) in an OLS regression with all coefficients at the 1 percent significance level, and we have $\mathrm{g}\left(U_{R E B, K}\right)=0.168 * \mathrm{~g}$ (oil price). Incorporating an oil factor into the regression as a proxy of capital utilization, the oil price (income-side) and supply-side approaches to the Russian growth might be integrated in a well defined manner.

We also measured Russian GDP gaps based on the production function and the Hodrick-Prescott filter. The potential growth rate of Russia's GDP is about 4 percent. The overheated growth for 2005Q1-2008Q3 resulted in the Lehman shock coupled with 
adverse oil shock. The Russian GDP has not yet reached its overheated peak level in 2008Q2 and its potential level based on the production function, while it might have already caught its potential level based on the Hodrick-Prescott filter in 2010, thanks to favorable changes in oil prices.

(Revised on February 17th, 2011.)

\section{Appendix}

Table A1 below shows the details of the regressions in this paper. The order of integration of the series is important for the selected regressions. We tested for unit roots by the commonly used Augmented Dickey-Fuller (ADF) tests. Table A2 below shows results using the lag length selected by the Schwarz information criterion. For all series of variables in levels we cannot reject the null of nonstationarity. In other words, all variables are nonstationary. Performing the tests for the first differences of variables, we reject the null of nonstationarity. Since all variables have to be differenced once to obtain stationarity, they are integrated of order 1, I (1).

To test whether the nonstationary variables in our regressions are cointegrated or spuriously related, we examined the properties of the regression residuals by the ADF test. Table A3 below reports our results in the cases with none of exogenous terms for regressions in this paper. For all regressions we can reject the null of no cointegration. In other words, the nonstationary variables of our regressions are cointegrated.

[Table A1 here]

[Table A2 here]

[Table A3 here]

\section{References}

Bessonov, V.A., 2004. On Dynamics of Total Factor Productivity in the Russian Trasition Economy [O dynamike sovokupnoi faktornoi proizvoditel'nosti v Rossiiskoi perekhodnoi ekonomike], Moscow: Institute of Economics of Transition Period. 
Bessonov, V.A., and Voskoboinikov, I.B., 2006. "Dynamics of fixed capital and investment in the Russian Transition Economy [Dinamika osnovnykh fondov i investii v Rossiiskoi perekhodnoi ekonomike]." Scientific Work, No. 97. Moscow: Institute of Economics of Transition Period.

de Broeck, M., and Koen, V., 2000. "The Great Contractions in Russia, the Baltics and the Other Countries of the Former Soviet Union: A View from the Supply Side." IMF Working Papers, 00/32.

Gavrilenkov, E., 2003. "Diversification of the Russian Economy and Growth."

Discussion Paper, No. 111. European Institute for International Economic Relations, University of Wuppertal.

Hanson, P., 2009. "Russia to 2020." Finmeccanica Occasional Paper.

Hodrick, R., and Prescott, E., 1997. "Post-war U.S. Business Cycles: An Empirical Investigation.” Journal of Money, Credit and Banking, 29 (1): 1-16.

Izyurmov, A., and Vahaly, J., 2008. "Old Capital vs. New Investment in Post-Soviet Economics: Conceptual Issues and Estimates." Comparative Economic Studies, 50: 79-110.

Kuboniwa, M., 2010. "Diagnosing "Russian disease": Growth and Structure of the Russian Economy Then and Now.” RRC Working Paper, No.28. Institute of Economic Research, Hitotsubashi University.

Lissovolik, Y., 2004. Doubling GDP: Putin's Mission Impossible, Moscow: United Financial Group.

LS (Labor Survey: Obsledovanie naseleniia po problemam zaniatosti), Moscow: Rosstat. various issues for 1999-2010.

Michaelides, P., and Millos, J., 2009. “TFP Change, Output Gap and Inflation In the Russian Federation (1994-2006).” Journal of Economics and Business, 61: 339-352.

NAR (National Accounts of Russia; Natsional 'nye scheta Rossii), Moscow: Rosstat. various issues.

Oomes, N., and Dynnikova, O., 2006. "The Utilization-Adjusted Output gap: Is the Russian Economy Overheating?" IMF Working Paper, WP/06/68.

REB (Russian Economic Barometer), 2010, Vol. 2.

SEP (Social and Economic Position of Russia), Moscow: Rosstat. various issues.

Weitzman, M., 1970. "Soviet Postwar Economic Growth and Capital-Labor Substitution." The American Economic Review, 60 (4): 676-692.

Wilson, D., and Purushothaman, R., 2003. "Dreaming with BRICs: the Path to 2050." Goldman and Sachs Global Economics Paper, No.99. 
Figure 1. Movement of Russian GDP for 1995Q1 - 2010 Q2

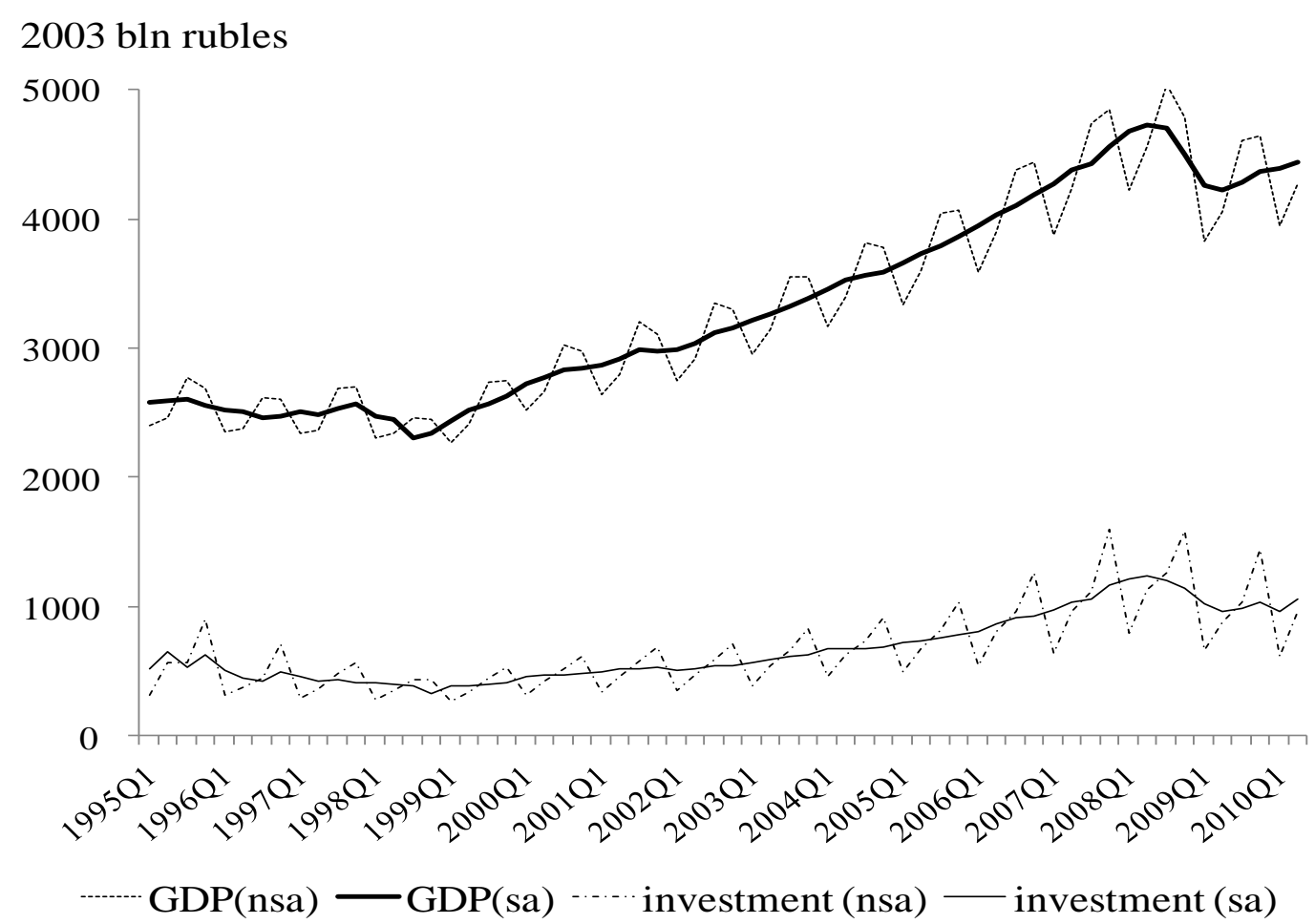

Figure 2. Utilization Rates (REB) and Labor Employment Rate

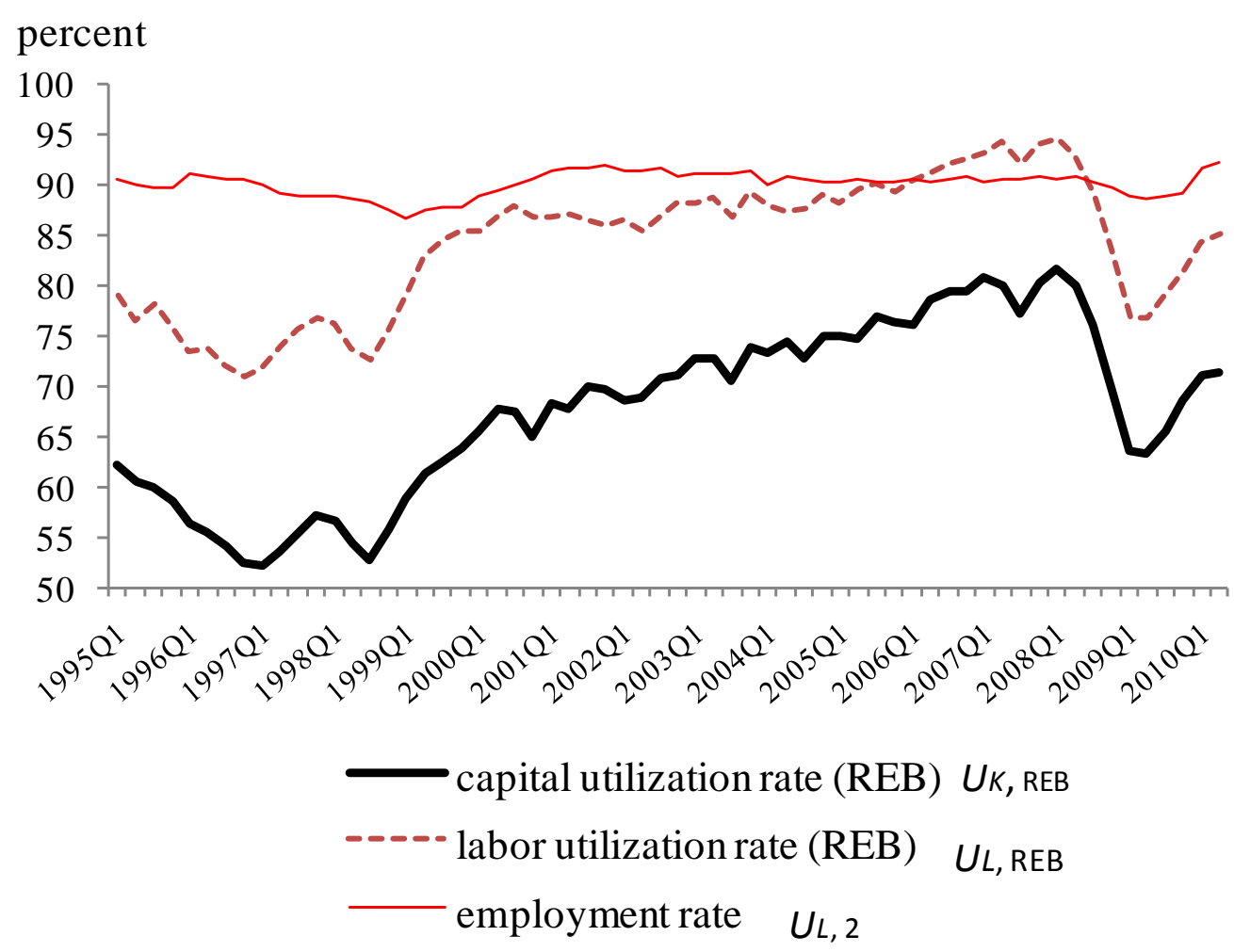


Figure 3. Russia's Capital Stock for 1995Q1 - 2010Q2

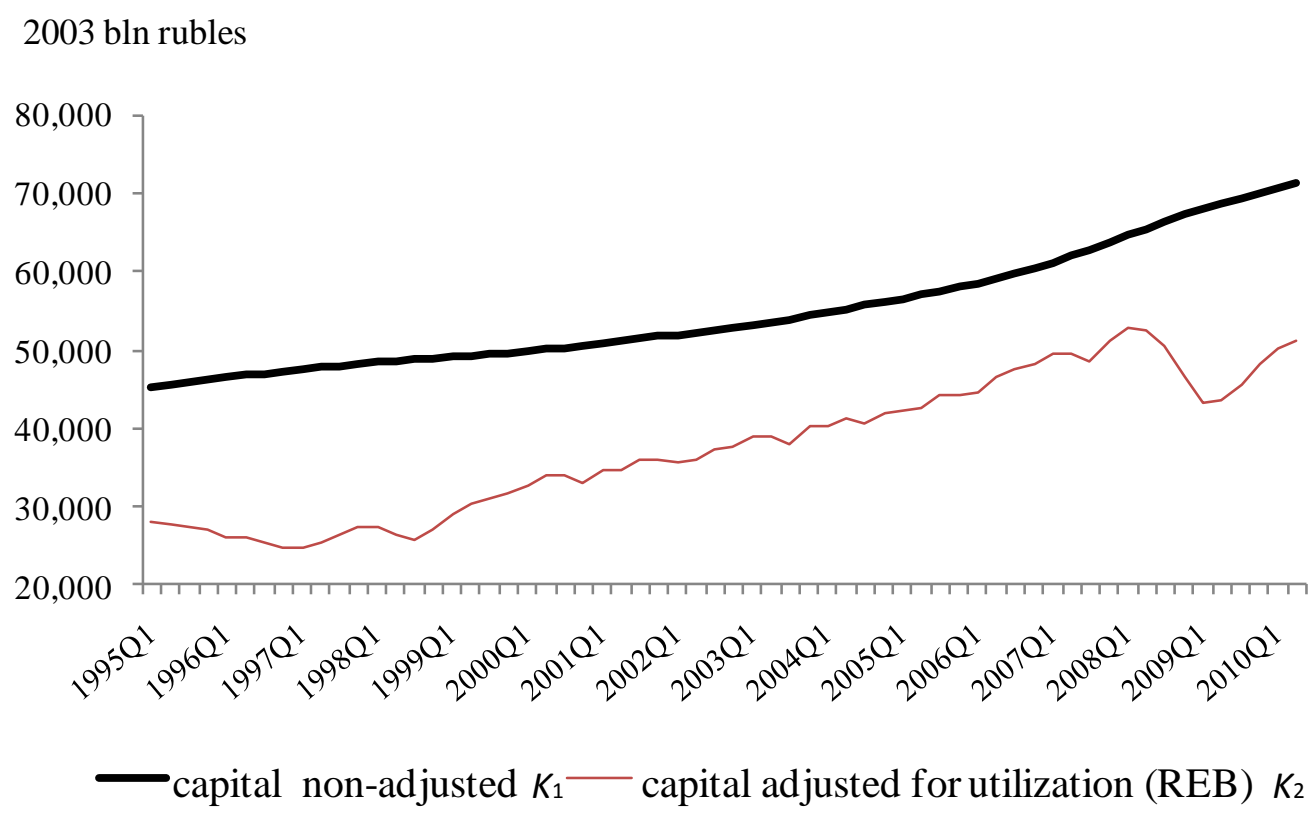

Figure 4. Labor and Employment in Russia for 1995Q1 - 2010Q2

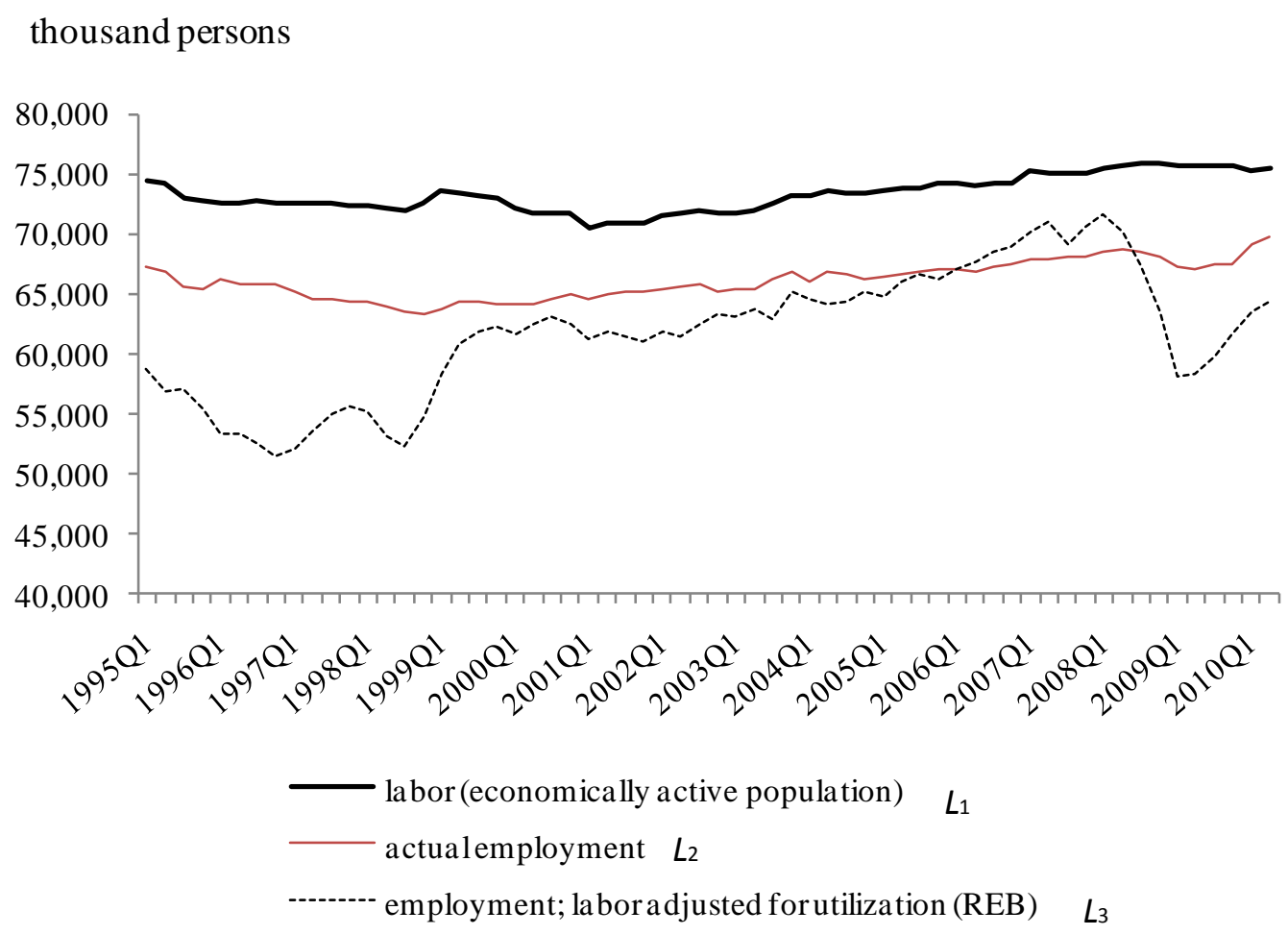


Figure 5. Labor Productivity and Capital-Labor Ratio: Capital Adjusted for Utilization (REB) and Labor Adjusted for Actual Employment

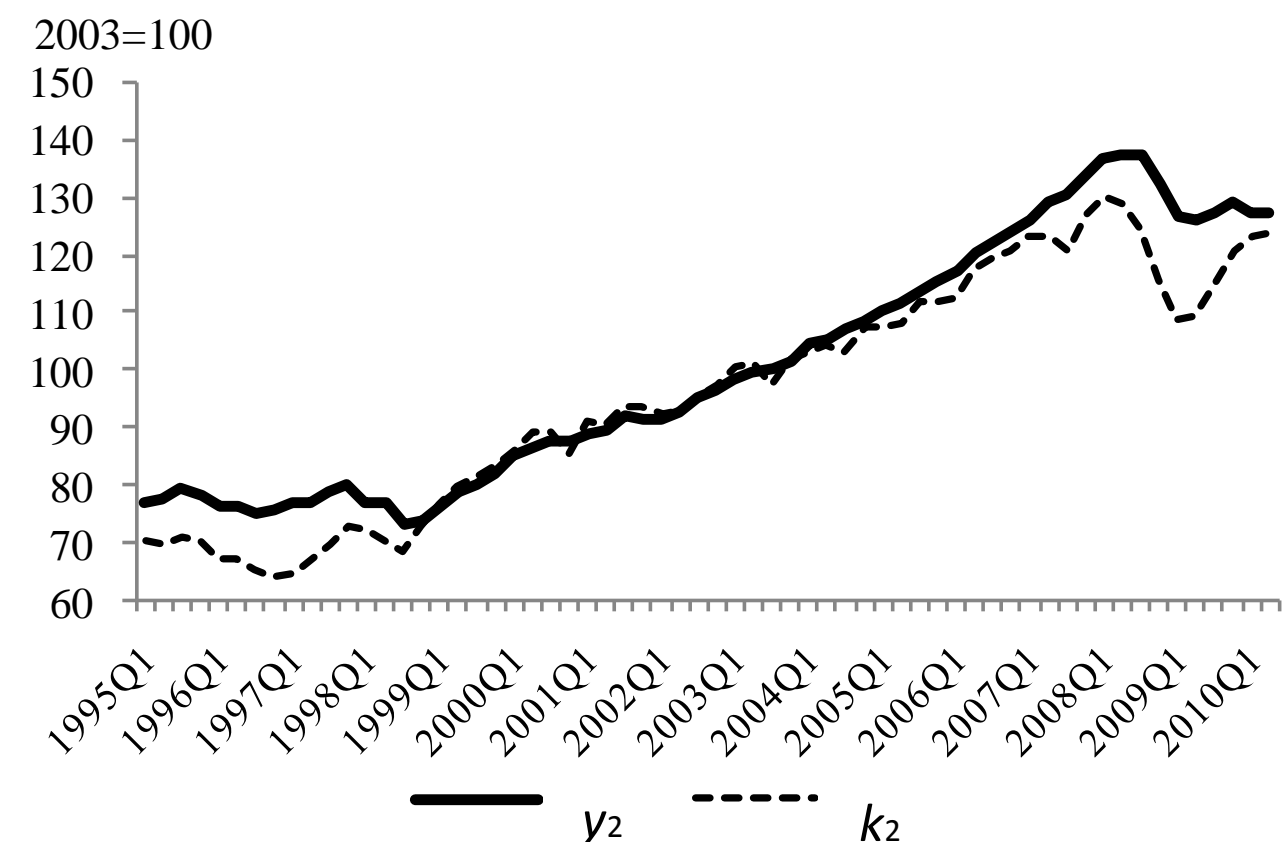

Figure6. Labor Productivity and Capital-Labor Ratio: Both Capital and Labor Adjusted for Utilization (REB)

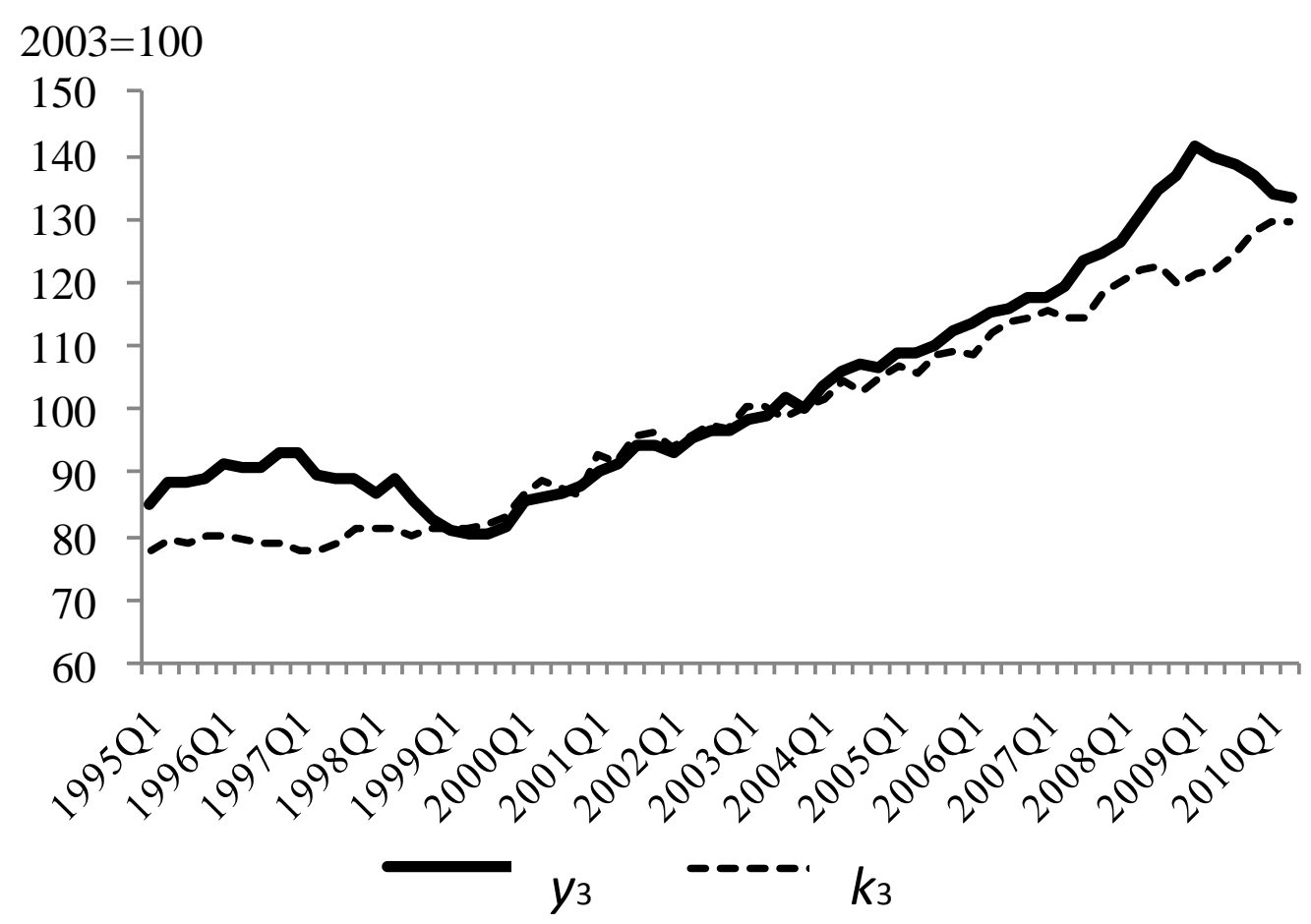


Figure 7. Actual and Fitted GDPs for 1998Q3-2008Q2 based on Equation (2)

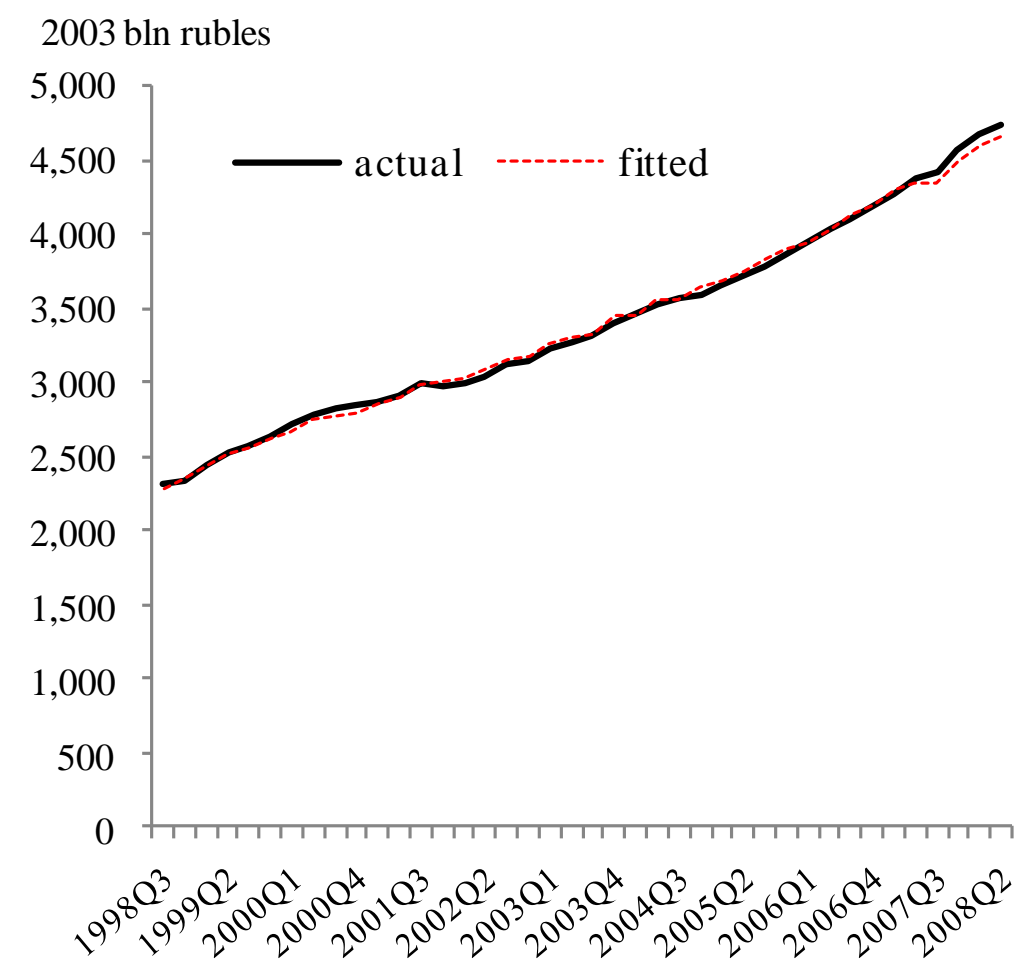

Figure 8. Actual and Fitted GDPs for 1995Q1-2010Q2 based on Equation (2)

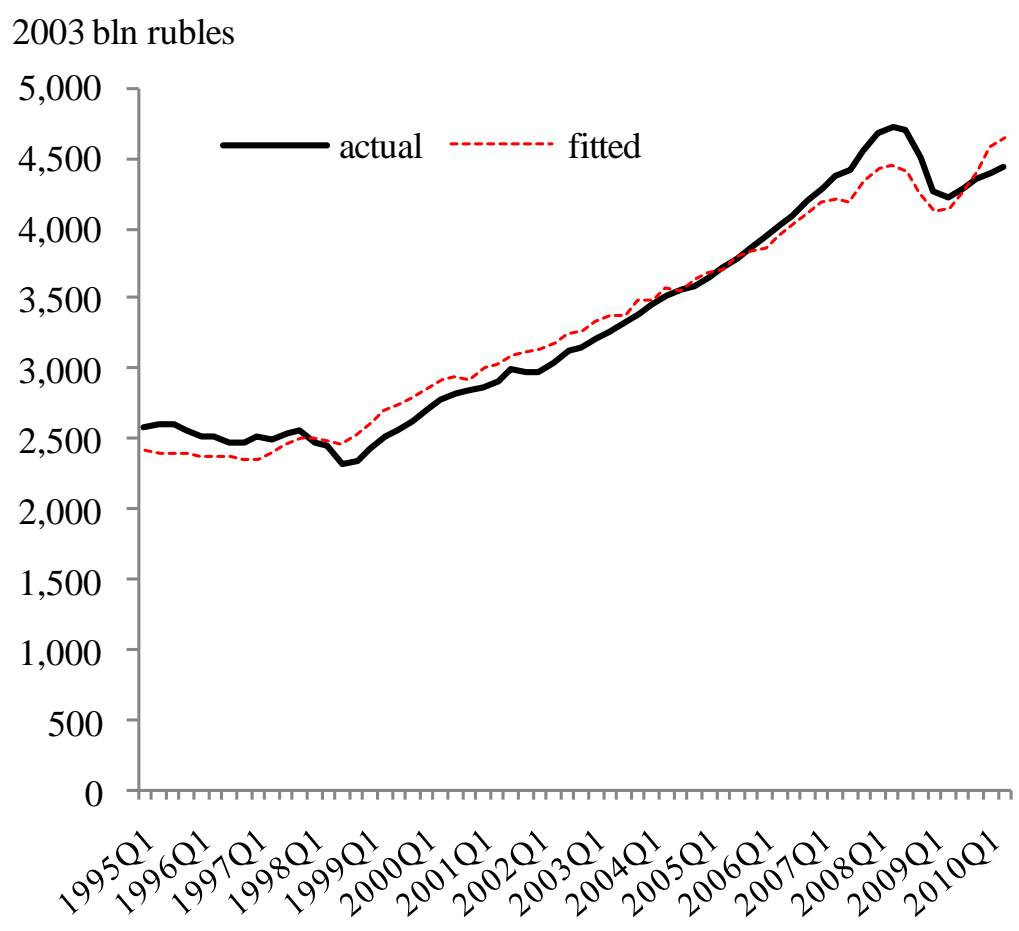


Figure 9. GDP Gaps in Russia

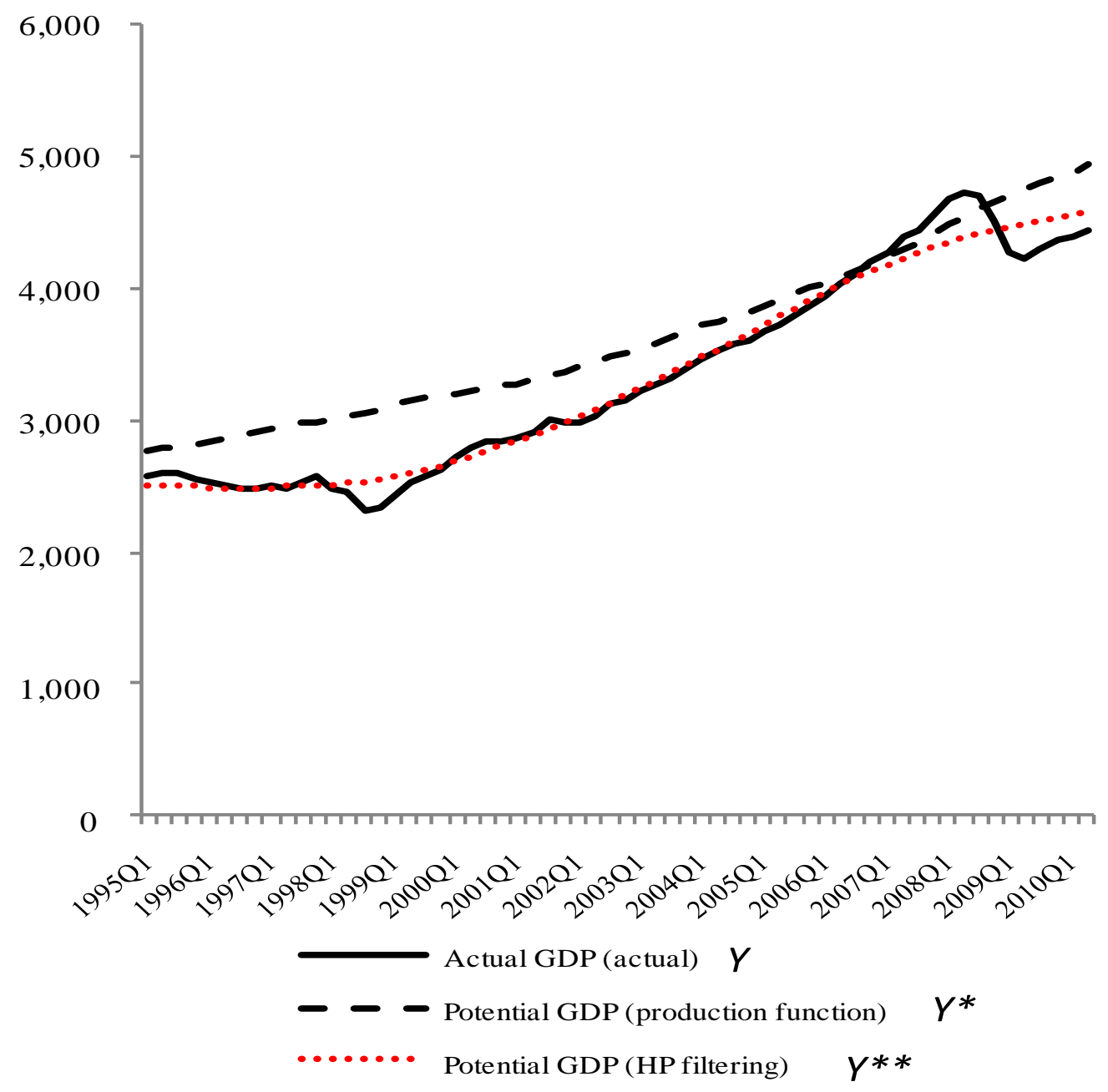

Table 1. Russian Growth Accounting based on Annual Average Growth Rates

\begin{tabular}{|c|c|c|c|c|c|c|c|c|c|}
\hline & \multicolumn{3}{|c|}{ growth rate } & \multicolumn{2}{|c|}{ distribution ratio } & \multicolumn{4}{|c|}{ contribution } \\
\hline & GDP & capital & labor & capital & labor & capital & labor & TFP & $\begin{array}{l}\text { stat. } \\
\text { error }\end{array}$ \\
\hline \multicolumn{10}{|c|}{ [1998Q3-2008Q2] } \\
\hline Equation (1) & 7.6 & 3.1 & 0.5 & 0.75 & 0.25 & 2.3 & 0.1 & 4.6 & 0.6 \\
\hline Equation (2) & 7.6 & 7.6 & 0.8 & 0.39 & 0.61 & 3.0 & 0.5 & 4.0 & 0.1 \\
\hline Equation (2a) & 7.6 & 3.1 & 0.8 & 0.64 & 0.36 & 2.0 & 0.3 & 4.6 & 0.7 \\
\hline Equation (3) & 7.6 & 7.6 & 3.1 & 0.34 & 0.66 & 2.6 & 2.1 & 3.4 & -0.5 \\
\hline \multicolumn{10}{|c|}{ [1995Q1-2010Q2] } \\
\hline Equation (2) & 3.6 & 4.0 & 0.2 & 0.44 & 0.56 & 1.8 & 0.1 & 2.5 & -0.7 \\
\hline
\end{tabular}


Table A1. Results for Regressions

\begin{tabular}{|c|c|c|c|c|c|c|}
\hline $\begin{array}{c}\text { Dependent } \\
\text { variable }\end{array}$ & $\begin{array}{c}\text { Independent } \\
\text { variable }\end{array}$ & Coefficient & Std. Error & t-Statistic & Prob. & Adj. $\mathrm{R}^{2}$ \\
\hline \multicolumn{7}{|c|}{ [Sample: 1998Q3-2008Q2] } \\
\hline \multirow[t]{3}{*}{$\log y_{1}$} & constant & -3.250 & 0.130 & -25.033 & 0.000 & 0.989 \\
\hline & $\log k_{1}$ & 0.751 & 0.263 & 2.858 & 0.007 & \\
\hline & $\lambda$ & 0.011 & 0.002 & 6.990 & 0.000 & \\
\hline \multirow[t]{3}{*}{$\log y_{2}$} & constant & -3.108 & 0.059 & -53.130 & 0.000 & 0.996 \\
\hline & $\log k_{2}$ & 0.394 & 0.059 & 6.672 & 0.000 & \\
\hline & $\lambda$ & 0.010 & 0.001 & 11.994 & 0.000 & \\
\hline \multirow[t]{4}{*}{$\log y_{2}$} & constant & -3.242 & 0.053 & -61.551 & 0.000 & 0.996 \\
\hline & $\log k_{2 \mathrm{a}}$ & 0.642 & 0.138 & 4.669 & 0.000 & \\
\hline & $\lambda$ & 0.011 & 0.001 & 14.083 & 0.000 & \\
\hline & dummy & -0.060 & 0.010 & -5.809 & 0.000 & \\
\hline \multirow[t]{3}{*}{$\log y_{3}$} & constant & -3.073 & 0.130 & -23.597 & 0.000 & 0.984 \\
\hline & $\log k_{3}$ & 0.338 & 0.153 & 2.206 & 0.034 & \\
\hline & $\lambda$ & 0.008 & 0.002 & 5.250 & 0.000 & \\
\hline \multicolumn{7}{|c|}{ [Sample: 1995Q1-2010Q2] } \\
\hline \multirow[t]{3}{*}{$\log y_{2}$} & constant & -2.941 & 0.089 & -32.861 & 0.000 & 0.954 \\
\hline & $\log k_{2}$ & 0.440 & 0.093 & 4.723 & 0.000 & \\
\hline & $\lambda$ & 0.006 & 0.001 & 5.306 & 0.000 & \\
\hline
\end{tabular}

Notes:

$y_{1}=Y / L_{1}, k_{1}=K_{1} / L_{1}$.

$y_{2}=Y / L_{2}, k_{2}=U_{K},{ }_{\mathrm{REB}} K_{1} / L_{2}, k_{2 \mathrm{a}}=K_{1} / L_{2}$.

$y_{3}=Y / L_{3}, L_{3}=U_{L}, R E B L_{1}, k_{3}=U_{K},{ }_{\mathrm{REB}} K_{1} / L_{3}$.

dummy $=1$ for 1998Q3-1998Q4; and dummy $=0$ otherwise. 
Table A2. Unit Root Tests for Variables for 1995Q1-2010Q2

\begin{tabular}{lccc}
\hline \multicolumn{1}{c}{ Variable } & Exogenous & Lag & t-statistic \\
\hline $\log y_{1}$ & constant, trend & 1 & -2.674 \\
$\mathrm{D}\left(\log y_{1}\right)$ & constant & 0 & $-4.573 * *$ \\
$\log y_{2}$ & constant, trend & 1 & -2.438 \\
$\mathrm{D}\left(\log y_{2}\right)$ & constant & 0 & $-5.143 * *$ \\
$\log y_{3}$ & constant, trend & 0 & -1.395 \\
$\mathrm{D}\left(\log y_{3}\right)$ & constant & 0 & $-6.554 * *$ \\
$\log k_{1}$ & constant, trend & 0 & 0.235 \\
$\mathrm{D}\left(\log k_{1}\right)$ & constant & 0 & $-5.233 * *$ \\
$\log k_{2}$ & constant, trend & 1 & -2.571 \\
$\mathrm{D}\left(\log k_{2}\right)$ & constant & 0 & $-5.709 * *$ \\
$\log k_{2 \mathrm{a}}$ & constant, trend & 0 & -0.364 \\
$\mathrm{D}\left(\log k_{2 \mathrm{a}}\right)$ & constant & 0 & $-5.573 * *$ \\
$\log k_{3}$ & constant, trend & 0 & -3.209 \\
$\mathrm{D}\left(\log k_{3}\right)$ & constant & 0 & $-9.494 * *$ \\
$\log k_{4}$ & constant, trend & 1 & -3.225 \\
$\mathrm{D}\left(\log k_{4}\right)$ & constant & 0 & $-5.502 * *$ \\
\hline $\mathrm{N}$ & & & \\
\hline
\end{tabular}

Notes:

**: the 1 percent significance level. *: the 5 percent significance level.

The lag length is generated by the Schwarz information criterion.

$\mathrm{D}(x)$ denotes the first difference of $x$.

Table A3. Unit Root Tests for Regressions

\begin{tabular}{lccr}
\hline \multicolumn{1}{c}{ Equation } & Sample & Lag & \multicolumn{1}{c}{ t-statistic } \\
\hline Equation (1) & 1998Q3-2008Q2 & 0 & $-3.128 * *$ \\
Equaion (2) & 1995Q1-2010Q2 & 3 & $-2.634^{* *}$ \\
Equaion (2a) & 1998Q3-2008Q2 & 0 & $-3.085^{* *}$ \\
Equaion (3) & 1998Q3-2008Q2 & 0 & $-6.114 * *$ \\
\hline
\end{tabular}

Notes:

**: the 1 percent significance level.

The lag length is generated by the Schwarz information criterion. 